\title{
The Effectiveness of Correctional
}

Programs*

\author{
JAMES RoBison \\ Research Associate, NCCD Research Center, Davis, Calif.
}

Supervisor, Bay Area Research Unit, California Department of Corrections, Oakland, 1965-68; Associate Specialist II, School of Criminology, University of California (Berkeley) , 1968-69

A.B. (Psychology), 1956, University of California (Los Angeles) ; M.A. (Psychology), 1969, University of Michigan; D. Crim., 1970, University of California (Berkeley)

\section{Gerald SMith}

Assistant Professor, Department of Sociology, University of Utah B.A., 1965, M.A. (Sociology), 1966, University of Louisville; D. Crim., 1969, University of California (Berkeley)

Justifications for the development of special correctional programs and for the choice of sentencing disposition for an individual offender are frequently based on claims of greater rehabilitative efficacy. While considerable evidence exists that some types of offenders have relatively more or less likelihood of recidivism than others, there is, as yet, almost no evidence that available correctional alternatives have any impact on those likelihoods. The article reviews findings from studies of correction in California for five critical choices in offender processing: (1) imprisonment or probation, (2) length of stay in prison, (3) treatment program in prison, (4) intensity of parole or probation supervision, and (5) outright discharge from prison or release on parole. The authors conclude that variations in recidivism rates among these alternatives are, for the most part, attributable to initial differences among the types of offenders processed and that the remaining differences in violation rate between programs may be accounted for by differences in interpreting an event as a violation or in officially designating it as such. No evidence was found to support claims of superior rehabilitative efficacy of one correctional alternative over another.

$\mathbf{T}$ HE INTRODUCTION of reform measures in correctional programs in the latter part of the nineteenth cen-

- Based on a special report by James Robison to the California Legislature Ways and Means Committee, Select Committee on Criminal Justice, 1969. tury was largely the result of a desire for humane treatment of offenders. The offender was no longer regarded as an evil person who "freely chose" to engage in criminal activities; rather, he was viewed as having been "socially determined" to take deviant 
roles and now in need of "treatment" to "reform" or "rehabilitate" him into a socially adequate individual. His change in status from an "evil" person to one who is "sick" was paralleled by the growth of a "correctional" system to handle the "patients." The retributive slogan, "Let the punishment fit the crime," was displaced by a new principle, "Let the treatment fit the needs of the offender," which called for educational training, psychotherapy (primarily group counseling), and community treatment (usually some variation of probation or parole).

These new correctional programs focused primarily on the offender; however, recent efforts have also been directed toward the community. ${ }^{1}$ How effective any of these various reform measures has been in rehabilitating offenders (i.e., in reducing the probability of recidivism) was not studied very rigorously until recently because of numerous problems of evaluation.

Assessment of the relative effectiveness of various correctional programs is difficult because adequate measures of performance have not been authoritatively established. Very often the attempt to measure the behavior of the system's clients is confounded by the reporting procedures of the system. The results of such research yield insights about the personnel of the system but tell us little about its clients. ${ }^{2}$

1 President's Commission on Law Enforcement and Administration of Justice, The Challenge of Crime in a Free Society (Washington, D.C.: U.S. Government Printing Office, 1967) .

2 J. Robison and P. Takagi, "Case Decisions in a State Parole System," California Department of Corrections, Research Division, Administrative Abstract, Research Report No. 31, 1968.
Research into the correctional system has been concerned with answer. ing these five basic questions about the behavior of convicted persons subjected to alternative procedures:

1. Will they act differently if we lock them up rather than place them on probation?

2. Will they recidivate less if we keep them locked up longer?

3. Do educating and "treating" in prison reduce recidivism?

4. Does supervising them more closely in smaller parole caseloads reduce recidivism?

5. What difference does it make whether we discharge prisoners outright or supervise them on parole?

The answers to these questions are not easy to obtain because of all the influences that act on the measuring instruments. Nevertheless, a review of current research will illustrate the problems of evaluation of correctional effectiveness and will yield insights into the probable effects of various penal measures.

\section{Lock Them Up?}

Deciding whether to place an offender on probation or to imprison him is not determined by the relative rehabilitative efficacy of the two approaches. The courts place only their "best risks" on probation; the persons who are imprisoned differ in many ways from those given probation. Hence a simple analysis of the difference in recidivism rates between prison and probation cases will not answer questions about their relative effectiveness. Exploring this difference requires control for case differences.

One possible way to control for case differences is to make random assignment of cases to either probation or prison, as in, for example, the Califor- 
nia Youth Authority's Community Treatment Project (CTP), which has been in operation since 1961 and has been widely acclaimed for its promise. After commitment to the Reception Center, wards were randomly assigned either to (1) a "control" group, confined in an institution and then given regular parole, or to (2) an "experimental" group, released immediately to small special caseloads in the community ( 9.5 parolees per agent, compared with 55 per agent under regular supervision).$^{3}$ A cohort follow-up has demonstrated statistically significant differences favoring community treatment. At the fifteen-months period, 30 per cent of male experimentals had "violated parole or had been unfavorably discharged," compared with 51 per cent of male controls (and 45 per cent of regular statewide Youth Authority releasees). At the 24-months period, these outcomes were 43 per cent and 63 per cent, respectively, again favoring the experimental group. If we take these findings at face value, we are forced to conclude that probation has been proven to be a more effective correctional program than imprisonment for reducing recidivism. But has it?

Within certain boundaries, the recidivism rate can be influenced by the decision-making authorities. ${ }^{4}$ The technical violation rate has been shown to vary between parole agents

3 California Legislature, "Analysis of the Budget Bill of the State of California for the Fiscal Year July 1, 1968, to June 30, 1969," 1969.

4 Robison and Takagi, supra note 2, and J. Robison, M. Gagerstrom, G. Smith, and R. Kingsnorth, "2943 PC Follow-up: Review of the First Year of Adjustment Subsequent to Consideration of Parole Termination," California Department of Corrections, Bay Area Research Unit, 1967. handling similar cases and has markedly influenced the recidivism rates of their wards. ${ }^{5}$ In the CTP study, the recidivism rates were managed in such a way as to make the experimentals appear favorable. "The bulk of control failures $(68 \%)$ was accounted for by the category of Parole Agent Casework Decision (i.e., agent's recommendation to the Youth Authority Board that a given ward's parole be revoked), although this same category accounted for no more than $29 \%$ of the Experimental failures." 6 In re-examination of the data, Lerman found that "the chance that an Experimental boy's offense will be handled in a 'revoking' manner is lower if the offense is low or moderate in severity. Experimentals are judged similarly to the Controls only when the offenses are of high severity."' The experimentals were no less delinquent in their behavior than the controls; in fact, they committed more "known" delinquent offenses than the controls (2.81 per experimental boy; 1.61 per control boy) ${ }^{8}$ This is probably an effect of increased supervision -i.e., if the controls had been watched as carefully, there would have been no differences between the two. The important point, however, is that an ideological belief in the effectiveness of community treatment apparently altered the experimental results.

$5 \mathrm{~J}$. Robison and P. Takagi, "The Parole Violator as an Organization Reject," University of California, School of Criminology, 1968.

6 R. Warren, T. Palmer, et al., "An Evaluation of Community Treatment for Delinquents," California Youth Authority, Community Treatment Project Research Report No. 7, 1966.

7 P. Lerman, "Evaluating the Outcome of Institutions for Delinquents," Social Work, July 1968.

8 Ibid. 
In the light of these facts CTP gives little support to the thesis that probation is superior to institutionalization for reducing the recidivism rate. There appears to be no difference between the two approaches. One might, however, still argue in favor of "community treatment" on humanitarian and economic grounds.

Another relevant project that attempted to test the relative effectiveness of community treatment was conducted by the Northern California Service League; it involved adult offenders given professional casework service in lieu of a jail or prison term.

It provided for the treatment of any adult offender referred by the Superior or Municipal Courts of San Francisco who had been found guilty of an offense other than one relating to drunkenness and whose sentence would ordinarily be a county jail or prison term, were the offender not referred to the project for treatment. . . The second condition, namely that the offender would ordinarily receive a jail or prison term were it not for referral to the project, was to insure that the group treated by the project would be the group that would ordinarily be going to jail or prison and would not include those who would ordinarily be given probation. ${ }^{9}$

Assignment was, thus, not random. Checks upon whether referrals were representative of those being confined revealed that project cases tended to be somewhat younger and included fewer minority ethnic group members, a disproportionately low number of narcotic offenders, and a disproportionately high number of property offenders (e.g., crimes against property, 67 per cent vs. 48 per cent for those jailed and imprisoned in the same

9 E. Conbrose, "Final Report of the San Francisco Rehabilitation Project for Offenders," Northern California Service League, 1966. year; assaultive crimes, 15 per cent vs. 16 per cent; sexual abuse, 4 per cent vs. 5 per cent; narcotics indulgence or abuse, 12 per cent vs. 25 per cent) . The attempt to evaluate outcome matched project cases with jail releasees on age, sex, race, type of offense, and time of release. By the criterion chosen (no arrests or only one or two arrests but no convictions), project cases $(\mathrm{N}=95)$ appeared to do better than jail releasees: 80 per cent favorable, compared with 70 per cent; however, the project sponsors consider the findings tentative and comment that the evaluative techniques are faulty.10 Nevertheless, it would be safe to conclude that project cases did just as well as those confined. The study does not support any claim that institutional confinement is more effective than community supervision.

\section{Keep Them Locked Up Longer?}

The phrase "optimum time for release" suggests that the releasing authority knows when that point in time has been reached and is ready to act on that knowledge. Implicit in it is the notion that there is a relationship between the amount of time served and the probability of recidivism. But is there?

The findings of the California Department of Corrections study of Advanced Release to Parole for the 1954-57 release years are shown in Table 1. The performance difference of 4 per cent in favor of early releases after six months is attributable to their being low risk cases. When baseexpectancy controls are introduced for quality of case, early release makes no difference. "All differences appear to be accounted for by base expectan-

10 Ibid. 
TABLE 1

Percentage of Completely Clean Parole Records within Six Months after Release to Parole in 1954-57 by SIPU Assignment and Types of Parole Release

\begin{tabular}{|c|c|c|c|c|c|}
\hline \multirow[b]{2}{*}{$\begin{array}{l}\text { Type of } \\
\text { Parole } \\
\text { Release }\end{array}$} & \multicolumn{2}{|c|}{ All Assignments (1954-1957) } & \multicolumn{3}{|c|}{ Type of Assignment (1954-1957) } \\
\hline & $\begin{array}{c}\text { No. } \\
\text { Released }\end{array}$ & $\begin{array}{l}\text { Per cent } \\
\text { "Clean" }\end{array}$ & $\begin{array}{l}\text { Small or } \\
\text { Medium } \\
\text { Caseloads }\end{array}$ & $\begin{array}{c}\text { SIPU } \\
\text { Large } \\
\text { Caseloads }\end{array}$ & $\begin{array}{c}\text { Non-SIPU } \\
\text { Large } \\
\text { Caseloads }\end{array}$ \\
\hline $\begin{array}{l}\text { Regular } \\
\text { Advanced } \\
\text { Difference }\end{array}$ & $\begin{array}{l}7,884 \\
3,116 \\
-\end{array}$ & $\begin{array}{c}68 \% \\
73 \% \\
\end{array}$ & $\begin{array}{r}70 \% \\
74 \% \\
4 \%\end{array}$ & $\begin{array}{r}68 \% \\
72 \% \\
4 \%\end{array}$ & $\begin{array}{r}69 \% \\
72 \% \\
3 \%\end{array}$ \\
\hline
\end{tabular}

cies or length of parole term variability." 11 This was found true when follow-up comparisons were extended to analysis of one-, two-, and three-year exposure periods, and regardless of the size of the parole caseload to which men were released.12

On the other hand, there is some evidence that the practice of keeping men in prison longer in itself increases the probability of recidivism. Jaman $^{13}$ recently compared parole performances, since 1957, of California first prison releases of persons originally committed for Robbery 1st or 2nd. (On June 30, 1968, 41.6 per cent of the adult felon prison population consisted of men in these offense categories. ${ }^{14}$ ) They were compared -according to whether they had served less or more than the median time in prison for the offense in the particular release year. Cohort follow-up for six-, twelve-, and 24-month periods consistently shows, by almost every

11 P. Mueller, "Advanced Releases to Parole," California Department of Corrections, Research Division, Research Report No. 20, 1965 .

12 Ibid.

13 D. Jaman, "Parole Outcome and Time Served by First Releases Committed for Robbery and Burglary, 1965 Releases," California Department of Corrections, Measurement Unit, 1968.

14 California Departrnent of Corrections, "California Prisoners, 1964-66," Research Division, Administrative Statistics Section, 1968. criterion (percentage "favorable," percentage returned with new commitment, percentage returned to finish term), a performance advantage favoring those released earlier. To counter the argument that such findings proved merely that the poorer risks were retained longer, Jaman extended the analysis to include control matching on age, ethnic group, base-expectancy level, parole region of release, and type of parole supervision received ("work unit" or "conventional" caseload) and applied it to prisoners released in 1965.

For all offense categories and in all follow-up periods, the percent of favorable outcome among the men who served less than the median time was greater than among those who served more than the median months. Almost half of the testable comparisons showed statistically significant differences. In fact, in the matched samples of men who had been committed for Robbery 1st, those who served less than the median months had a much higher percent of favorable outcome in all three follow-up periods.15

It is difficult to escape the conclusion that the act of incarcerating a person at all will impair whatever potential he has for crime-free future

15 D. Jaman, "Parole Outcome for First Releases for Selected Commitment Offenses by Time Served before First Release," California Department of Corrections, Rescarch Division, Measurement Unit, 1968. 
adjustment and that, regardless of which "treatments" are administered while he is in prison, the longer he is kept there the more will he deteriorate and the more likely is it that he will recidivate. In any event, it seems almost certain that releasing men from prison earlier than is now customary in California would not increase recidivism.

The likelihood of recidivism, however, may play relatively little part in the decision to retain many prisoners beyond their legal minimum term.

Sheldon Messinger points to another "hardly surprising" consideration -order within the prisons:

The felt need to maintain control over inmates moves prison officials to seek discretion over sentencing. . . . Prison officials are charged with the management of prisons; whatever the ultimate ends of imprisonment, from the officials' point of view a first requisite is effective influence over inmate conduct. So long as inmates desire freedom, restrictions of freedomthreatened and actual - will provide a possible strategy for control, for effective influence; and the correctional establishment as a whole is premised on the desire of inmates for freedom.10

Thus, just as prison overcrowding creates a pressure for either shorter average terms or increased capital outlay, the need for inmate control creates a pressure for lengthened confinement to maintain, by example, incentives for cooperative conduct.

\section{Do Something with Them Inside?}

Group counseling has been one of the most widely applied and recommended prison treatment techniques. Elements of this treatment (e.g., ventilation of feelings and help toward

\footnotetext{
16 S. Messinger, "Strategies of Control," University of California, Center for the Study of Law and Society, 1968.
}

self-understanding) were presumed to advance "rehabilitation" and, secondarily, to support institutional order by helping prisoners "adjust to the frustrations" and "improve the emotional climate of the institution." 17 To assess its effect on the primary goal of rehabilitation (operationally defined as the reduction of recidivism or the probability of recidivism), it is necessary to design an experimental situation utilizing rigorous controls. Only infrequently are treatment programs subject to the types of experimental testing necessary for valid evaluation. $^{18}$ Much of the published research on group counseling in a prison setting deals with simple descriptions of the program, ${ }^{19}$ theoretical justifications, 20 or shoddy "evaluations" without an adequate control group and random assignment of cases.

A recent study conducted to test the effect of group counseling in prison on postrelease behavior used a randomized assignment procedure and an adequate control group. ${ }^{21}$ It is a true cohort follow-up $(\mathrm{N}=968)$, with 36-months outcome obtained for each subject regardless of whether he was in custody, still on parole, or discharged from parole. All the subjects were from one prison, "a mediumsecurity institution with its popula-

17 A. Fenton, "Group Counseling-A Preface to Its Use in Correctional and Welfare Agencies," Sacramento, Calif., Institute for the Study of Crime and Delinquency, 1961.

18 L. T. Wilkins, Evaluation of Penal Measures (New York: Random House, 1969). 19 G. Sykes, The Society of Captives (New York: Atheneum, 1966) .

20 R. R. Korn and L. W. McCorkle, Criminology and Penology (New York: Holt, Rinehart, and Winston, 1966), ch. 20.

21 G. Kassebaum, D. Ward, and D. Wilner, Prison Treatment and Its Outcome (to be published by John Wiley). 
TABLE 2

Postrelease Status at 36 Months by Treatment Status (in Percentage)

\begin{tabular}{|c|c|c|c|c|c|}
\hline \multirow[b]{2}{*}{ Returned to Prison } & \multicolumn{5}{|c|}{ Treatment Category } \\
\hline & $\begin{array}{l}\text { "C"' } \\
\text { Quad }\end{array}$ & $\begin{array}{l}\text { Voluntary } \\
\text { Non-partici- } \\
\text { pation }\end{array}$ & $\begin{array}{l}\text { Community } \\
\text { Living }\end{array}$ & $\begin{array}{l}\text { Research } \\
\text { Counseling }\end{array}$ & $\begin{array}{l}\text { Regular } \\
\text { Counseling }\end{array}$ \\
\hline $\begin{array}{l}\text { With New Term } \\
\text { To Finish Term }\end{array}$ & $\begin{array}{l}16 \% \\
31\end{array}$ & $\begin{array}{l}18 \% \\
37\end{array}$ & $\begin{array}{l}27 \% \\
29\end{array}$ & $\begin{array}{l}20 \% \\
31\end{array}$ & $\begin{array}{l}15 \% \\
34\end{array}$ \\
\hline $\begin{array}{l}\text { After Discharge from } \\
\text { Parole }\end{array}$ & 1 & 1 & 3 & - & - \\
\hline \multicolumn{6}{|l|}{ Major Problems } \\
\hline $\begin{array}{l}\text { During Parole } \\
\text { After Discharge from }\end{array}$ & 5 & 3 & 10 & 5 & 6 \\
\hline Parole & 4 & 7 & 1 & 1 & 4 \\
\hline \multicolumn{6}{|l|}{ Minor Problems } \\
\hline $\begin{array}{l}\text { Dn ring Parole } \\
\text { After Discharge from }\end{array}$ & 7 & 3 & 7 & 8 & 9 \\
\hline Parole & 11 & 8 & 7 & 13 & 10 \\
\hline \multicolumn{6}{|l|}{ No Problems } \\
\hline $\begin{array}{l}\text { Still on Parole } \\
\text { Discharged from Parole }\end{array}$ & $\begin{array}{r}4 \\
21\end{array}$ & $\begin{array}{r}5 \\
18\end{array}$ & $\begin{array}{r}3 \\
12\end{array}$ & $\begin{array}{r}4 \\
18\end{array}$ & $\begin{array}{r}4 \\
18\end{array}$ \\
\hline $\begin{array}{l}\text { Total } \\
N=955^{b}\end{array}$ & $\begin{array}{l}100 \% \\
(269)\end{array}$ & $\begin{array}{l}100 \% \\
(173)\end{array}$ & $\begin{array}{l}100 \% \\
(68)\end{array}$ & $\begin{array}{l}100 \% \\
(171)\end{array}$ & $\begin{array}{l}100 \% \\
(274)\end{array}$ \\
\hline
\end{tabular}

a Percentage totals are rounded.

b Not including: Dead $=8$, Incomplete Information $=5$.

tion an almost perfect representation of modal departmental prisoner characteristics" 22; hence, there was no control group of nonimprisoned felons. While in prison the men were randomly assigned to (l) small counseling groups (Research Group Counseling, $N=171)$, (2) large groups (Community Living, $N=68)$, and (3) a control group (C-Quad, $\mathrm{N}=269$ ) where no counseling was given; the remainder of the men in the sample chose either to join group counseling (Regular Group Counseling, $N=274$ ) or to not participate at

22 The parole performance of the sample after thirty-six months was nearly identical with that in an earlier study of all men $(\mathrm{N}=1,810)$ released to California parole in 1956 . all (Voluntary Nonparticipation, $\mathrm{N}=173$ ). The study sample was limited to those who had at least six months' exposure to programing; the average number of group counseling sessions was forty. The results of the study are shown in Table 2.

There were no differences in parole outcome by treatment status measured at $6,12,24$, and 36 months after release, ... no treatment or control group differences on the number of misdemeanor or felony arrests recorded in the parole records, no differences in total number of weeks spent in jail, and no differences in most serious disposition received within three years after release. ${ }^{28}$

The researchers concluded:

23 Kassebaum et al., op. cit. supra note 21. 
Thousands of inmates and hundreds of staff members were participating in this program at a substantial cost to the Department of Corrections in time, effort, and money. ... Contrary to the expectations of the treatment theory, there were no significant differences in outcome for those in the various treatment programs or between the treatment groups and the control group.

Furthermore, contrary to sociological expectations, participation in group counseling and community living did not lessen even the limited endorsement of the inmate code, nor did it result in a demonstrable decrease in frequency of prison discipline problems. . . .

It would seem that in order for the Department of Corrections to continue to justify the widespread use of group counseling some new arguments must be advanced, such as "participation in group counseling gives custodial officers a real part in the treatment program and seems to improve their morale" or "group sessions add a little variety to inmate life and take up time."24

Nevertheless, the advocates of "treatment" programs can still argue that if group counseling improved in overall quality, it would indeed have an impact on recidvism.

The correctional treatment program just discussed is not atypical; it is unusual only in that it was subjected to a rigorous evaluation. Walter Bailey evaluated one hundred reports on correctional programs and outcome and found no solid indications of treatment efficacy ${ }^{25}$; Robert Martinson completed a similar study for

24 D. Ward, "Evaluation of Correctional Treatment: Some Implications of Negative Findings," Proceedings of the First National Symposium on Law Enforcement Science and Technology (Washington, D.C.: Thompson Book Co., 1967).

25 W. Bailey, "Correctional Outcome: An Evaluation of 100 Reports," University of California, Los Angeles, School of Social Welfare. the New York Governor's Special Committee on Criminal Offenders. ${ }^{28}$ Despite the continuing popularization of various treatment programs and the increased attention devoted to more rigorous designs for their evaluation, there are still no treatment techniques which have unequivocally demonstrated themselves capaable of reducing recidivism.

One of the major proposed efforts of the California Department of Corrections in institutional treatment is "medical-psychiatric" programing despite the absence of any evidence that its current model for such operations, the California Medical Facility, is superior in rehabilitative efficacy to routine prison programing. ${ }^{27}$ Professionalization and upgrading of treatment services are defensible on the grounds of important secondary objectives-special client needs and benefits-but it is doubtful that these. services are useful for reducing recidivism.

Processing an offender as ill (and he may, in fact, be ill) is hardly an advance over processing him as evil (and he may also, in fact, be evil). Neither formulation has much relevance in prison, since the inmate's primary status is that of a warehoused object. The California Department of Corrections plans to confer openly the patient status of "medicalpsychiatric" bed upon many who are now looked upon as only inmates ("general purpose" beds). The change in nomenclature may enhance the Department's image and will certainly spiral its costs, but any measurable

26 R. Martinson, Department of Sociology and Anthropology, City College of New York (personal communication) .

27 Similarly, there has been no evidence that the Department's Outpatient Psychiatric Clinics have any effect on recidivism. 
improvement in performance is unlikely.

Just as, historically, the number of witches rose as a consequence of an increase in the number of witch hunters and then declined, not in response to the hunters' rehabilitative efforts but rather as a consequence of corrective excesses that thinned the ranks of the witch hunters, ${ }^{28}$ correction may be approaching a turning point. Yet even today, we find passages such as the following, freshly in print:

Society's perception of criminals is changing. Criminals now can be seen as bad or sick. If they are bad, they require custody; if they are sick, they require treatment. The treatment-versus-custody controversy has raged in the Corrections field for several decades, but today the treatment advocates appear to be winning. ${ }^{2 \theta}$

Since nothing much is won if either side wins, maybe it's time to call off the game.

The narcotic addict has recently been transferred from the ranks of the bad to those of the sick, through little more than a change in the procedural labels: civil rather than criminal commitment; outpatient rather than parole supervision. Opposition to commitment for a treatment not proven effective has been voiced on the grounds that it is cruel and unusual punishment, that it denies to a person "accused" of illness the

28 "With the rise of rationalism, and the disbelief in a personal God, came a corresponding disbelief in his opposite, the Devil. ... A decline in the acceptance of miracles meant a decline in the acceptance of spells." P. Hughes, Witchcraft (Baltimore: Penguin Books, 1965), p. 42.

29 M. Mathews, "Correctional Rehabilitation: Boom or Bust?" Federal Offenders Rehabilitation Program, Fourth Annual Conference. San Antonio, 1968. stringent legal protections afforded a person accused of crime, and that it is hardly different from imprisonment. ${ }^{30}$

In this movement to civil commitment, California was, as usual, in the forefront, having established in 1961 a model that was recently copied in New York. The program, the California Rehabilitation Center (CRC), has recently been evaluated. Findings from a three-year cohort follow-up on CRC program performance of 1,209 first releasees to outpatient status indicated:

1. Seventeen per cent received a discharge from the program after completing three continuous years on outpatient status.

2. Sixty-seven per cent were returned to the CRC.

3. Thirty-three per cent received a new criminal conviction during their first release (22 per cent misdemeanors and 11 per cent felonies).

4. Seventy-one per cent were detected as having used drugs illegally (63 per cent opiates and 8 per cent other dangerous drugs or marijuana).

5. Characteristics most strongly related to completing the three-year period successfully were: being white; staying at CRC a short time; living with one's spouse; living outside of Los Angeles, Orange, San Francisco, or Sacramento counties; and working 75-100 per cent of the time. ${ }^{31}$

The findings, applicable only to first releasees, speak for themselves. Those returned to the center perform even more poorly, of course, upon subsequent release. For example, of all men released in 1966, 50 per cent

30 J. Kramer, J. Berecoches, and R. Bass, "Civil Commitment for Addicts," American Journal of Psychiatry, December 1968.

31 J. Berecoches, California Department of Corrections, Research Division, 1968 (personal communication). 
were returned before a single year in the community had elapsed; the rates were 48 per cent for first releasees, 54 per cent for second releasees, and 61 per cent for third releasees. ${ }^{32}$ Note also (see item 3 above) that one out of three shuttled from the ranks of the sick to the ranks of the bad-"new criminal conviction"-though relatively few to the extent of a felony.

When such results are interpreted as " a modest degree of success," 33 the emphasis certainly belongs on "modest," and one must also ask, "results more successful than what?" That a treatment of this caliber continues to expand and obtain funding makes it obvious that demonstration of effectiveness is a token promise rather than a consequential issue in determining where public investment will be placed. There are now two "habits" to support-the ailment and the costly treatment.

While group counseling has been the most popular special treatment in prison programing, reduced caseload size represents the major approach in parole and probation to the problem of curbing recidivism. Findings on the efficacy of this approach will be reviewed next.

\section{Watch Them More Closely Afterward?}

The question of caseload size has been more exhaustively studied than any of the others, and hopes attached to caseload reduction have served to justify numerous demonstration projects. These projects typically ask

$32 \mathrm{~J}$. Berecoches, R. Bass, and G. Sing, "Analysis of First-Year Experience of All Released from California Rehabilitation Center to Outpatient Status in 1966," California Rehabilitation Center, Narcotic Addict Outpatient Program Report No. 8, 1968.

33 Kramer et al., supra note 30. complicated questions about the nature as well as the "intensity" of the supervision technique and explore offender-variable questions as well.

California has led the field in experimentation with caseload size in parole; for the past fifteen years, the Department of Corrections has been involved in manipulation of caseload size. The Special Intensive Parole Unit (SIPU), conducted from 1953 to 1964 in four phases, provides interesting information about the effects of variation in caseload size on recidivism. Following is a summary of the results of each phase of this project:

Phase One (SIPU I) - Provided for random assessment of cases released from the Department of Corrections to special fifteen-man caseloads (experimental) or the regular ninety-man caseloads. Cases remained in an experimental caseload for three months (believed to be the most vulnerable months for failure) and were then transferred to a regular caseload. An evaluation of Phase One revealed that the reduced caseloads had no measurable effect on parole outcome.

Phase Two (SIPU II)-The experimental caseloads were increased to thirty men, and the length of stay was increased to six months before transfer to a regular caseload. Again, no evidence of the superiority of the reduced caseload was demonstrated.

Phase Three (SIPU III)-The experimental caseloads were increased to thirty. five men, and the length of stay was increased to one year before transfer to a regular caseload. A two-year follow-up revealed that reduced caseload parolees did slightly better than those on regular caseloads and that the improvement was attributable to medium-risk parolees.

Phase Four (SIPU IV)-Attempts were made to explore the effects of parolee and officer types on case outcome. Caseload size was reduced to thirty and fifteen, and 
TABLE 3

Actual Parole Performance by Caseload Size

\begin{tabular}{lll} 
Type of Parole Supervision & No. Released \\
${$\cline { 1 - 1 }$} }$ & & 2,948 \\
Conventional Supervision & & 4,353 \\
Total & 7,301
\end{tabular}

officers and parolees were matched on characteristics thought to be favorable to parole outcome. The results of the study indicated that these characteristics did not measurably affect parole outcome and that the only variable which mattered was the amount of time an officer had to devote to supervision. The fifteen-man caseload did no better than the thirtyman caseload. ${ }^{34}$

Phase Four of the study has been criticized for lack of precision. ${ }^{35}$ There is also evidence that SIPU agents were responding to violations by their parolees in the same fashion as the Youth Authority's Community Treatment Project agents.38 Thus, it is not known whether significant findings occurred because parolees were behaving differently or because parole agents wers reacting differently to violations.

Despite the absence of good evidence supporting reduced caseloads, the California legislature in 1964 gave approval to the Work Unit program in parole. The result was that half the adult male parolees in the state were placed under reduced-caseload supervision, which required the hiring of many parole agents. The assignment

34 See S. Adams, "Some Findings from Correctional Caseload Research," Federal Probation, December 1967.

35 Ibid.

36 See text supra at notes 4-8; also, J. Robison, Progress Notes toward the Proposed Study of Parole Operations, California Department of Corrections, Bay Area Research Unit, 1965. of cases to the Work Unit program (average caseloads of about thirty-five based on an elaborate grading system whereby each case is assigned points according to the seriousness of the offense and other factors) was left to the regional classification representative. Thus, Work Unit cases are different from Conventional Unit cases (i.e., regular supervision caseloads averaging about seventy cases), and a comparison of performance for the two has to take this difference into account. In 1965, its first year of operation, there were 2,948 prison releases to Work Unit parole supervision, and 4,353 to Conventional supervision. The performance figures for the two types of supervision, based on a oneyear cohort exposure period, are presented in Table $\mathbf{3 .}{ }^{37}$

The difference in performance between the two types of supervision appears slight; nevertheless, the $\mathbf{3 . 2}$ per cent advantage in favorable outcome of Work Unit over Conventional is statistically significant. In interpreting these data, however, we must remember that the two populations are not directly comparable. For example, all persons classified as having a high potential for violence were assigned to the Work Unit program, which was found to be composed of better-risk parolees as measured by an actuarial prediction device (California Base Expectancy 61A). When

37 Robison and Takagi, supra note 2. 
controls for parolee risk level were introduced, the difference in favorable outcome between the Work Unit and the Conventional Unit was erased, and conventional supervision was found to have a significantly lower rate of technical prison return.88

In 1964 the federal probation system inaugurated the San Francisco Project, experimenting with caseloads of four sizes and random assignment. Like the Work Unit program, the project experienced an increase in the technical violation rates accompanying reduction in caseload size:

The minimum supervision caseload has a violation rate of $24.3 \%$; and the "intensive" caseload, a violation rate of $37.5 \%$. ... In the "ideal" caseloads some five or six times as much attention, as measured by direct contact with the offender and with others about him, did not produce a reduction in violations; and in the "intensive" caseloads, despite fourteen times as much attention as provided the minimum supervision cases, the violation rate not only failed to decline significantly, but increased with respect to technical violations. . . . 39

The researchers concluded that the technical violation rate was a function of the amount of supervisioni.e., the intensified supervision enabled agents to discover a greater number of minor technical violations. Caseload groupings did not differ in regard to nontechnical violations. ${ }^{40}$ Thus the small caseload was not demonstrated to be more effective in reducing recidivism.

38 Ibid.

39 J. Lohman, A. Wahl, R. Carter, and S. Lewis, "The Intensive Supervision Caseload: A Preliminary Evaluation," University of California, School of Criminology, San Francisco Project No. 11, 1967.

40 Ibid.

\section{Cut Them Loose Officially?}

California prides itself on its extensive use of aftercare; about 90 per cent of male felons released from prison in recent years were released to parole supervision. Relatively little attention has been given to comparing men officially discharged from prison with men released on parole.

From 1960 through 1966, 4,854 male felons were discharged from prison at expiration of sentence. ${ }^{11}$ Of these, 47 per cent were first releases, and it seems reasonable to assume that many of these men were kept the full time because of problems in their prison adjustment or concerns about releasing them. More than half the prison discharges had been previously returned from parole as violators-10 per cent with a new commitment and 43 per cent to finish their original term. One out of every five men who are returned to prison as technical violators is subsequently discharged from prison and the remainder are reparoled, compared to one out of ten who are returned with new commitment and one out of twelve leaving on first prison release. ${ }^{42}$

In general, then, one would expect men discharged from prison to be poorer risks than those placed on parole. While cohort follow-up is routinely available only for parolees, some return-to-prison data are available from the California Department of Corrections. Examination of these data indicate that discharged men have fewer return-to-prison dispositions than men released to parole supervision. This does not mean that men discharged from prison are bet-

\footnotetext{
41 California Department of Corrections, supra note 14.

42 These proportions vary slightly from year to year.
} 
ter risks. The difference can most likely be accounted for by the circum. stance that men in discharged status are not subject to administrative returns as are technical violators of parole.

In a more detailed study of men discharged or paroled from prison in California (781 discharged vs. 2,858 paroled), Mueller found that, during the first two years, discharged cases had a more favorable postinstitutional outcome (i.e., no trouble or no disposition with a sentence over 89 days) than cases released to parole. ${ }^{13}$ However, after three years there was no difference between the two groups in postinstitutional dispositions. The parolees' less favorable dispositions during the first two years were probably attributable to their "return to finish term," a disposition not possible for discharged men.4

The threshold of criminal or antisocial behavior that may result in return to prison is obviously higher for the ex-prisoner who is no longer officially under commitment to a correctional system. Does the convenience offered by administrative return to confinement offer sufficient protection to warrant its expense? Are we paying more for protection than it is worth?

\section{Conclusion}

In the opening section of this essay we noted that reform movements have been generated primarily by humanitarian rather than pragmatic considerations. "Treatment," the presumed antithesis of "punishment," becomes the banner under which such a movement takes shape, and the slogan "Let the treatment fit the offender"

43 Mueller, supra note 11.

44 Ibid. replaces "Let the punishment fit the crime." Punishment and treatment, however, are not opposites; the opposite of punishment is reward, and the "law of effect" posits the utility of both in shaping future behavior. Since punishment may be a rehabilitative tool, to talk of punishment versus rehabilitation is foolish. But to speak of reward vis-à-vis offenders becomes awkward, since it plays havoc with the concept of deterrence: openly rewarding persons to stop being criminals would seemingly impel others to commit criminal acts in order to secure the benefits offered for retirement from crime. Consequently, it becomes politically more convenient or less embarrassing to introduce the concept of treatment to counterbalance punishment. Punishment is manifestly unpleasant and may or may not "work," whereas treatment, while not intrinsically pleasant, escapes the definitely unpleasant connotations of punishment; furthermore, it is impliedly effective: treatment; almost by definition, is that which results in improvement of a condition. Thus, treatment gains an aura of being both nicer (more humane) and better (more effective).

In correctional practice, treatment and punishment generally coexist and cannot appropriately be viewed as mutually exclusive. Correctional activities (treatments) are undertaken in settings established as places of punishment. Restriction of freedom is a punishment, no matter whether it is imposed by physical confinement (jail or prison) or by surveillance of movement in the community (probation or parole). The punitive conditions are viewed as necessary for the administration of treatment, and the treatments are believed to account for whatever favorable results occur. 
The real choice in correction, then, is not between treatment on one hand and punishment on the other but between one treatment-punishment alternative and another.

Analysis of findings in a review of the major California correctional programs that permit relatively rigorous evaluation strongly suggests the following conclusion: There is no evidence to support any program's claim of superior rehabilitative efficacy.

The single answer, then, to each of the five questions originally posed"Will the clients act differently if we lock them up, or keep them locked up longer, or do something with them inside, or watch them more closely afterward, or cut them loose officially?"-is: "Probably not."

Examination of correctional programs in states other than California would probably yield essentially similar results and the conclusion may generally apply. There is considerable evidence that different types of offenders have markedly different likelihoods of recidivating, and there can be little doubt that the different available correctional program options have markedly different degrees of unpleasantness associated with them. Since the more unpleasant or punishing alternatives are more likely to be invoked for those offenders with serious present offenses or multiple past offenses, it is natural that different success rates and apparently different degrees of effectiveness will attach to some alternatives, though these differences of effectiveness are illusory. Since the more unpleasant or punishing alternatives tend also to be the more expensive, the choice of appra priate disposition for offenders should be determined by the amount of punishment we want to impose and the amount of money we are prepared to spend in imposing it; it should not be obscured by illusions of differential rehabilitative efficacy. ${ }^{45}$ If the choice is, in fact, merely between greater and lesser punishments, then the rational justification for choosing the greater must, for now, be sought in concepts other than rehabilitation and be tested against criteria other than recidivism.

$45 \mathrm{~J}$. Robison, "It's Time to Stop Counting," Special Report to California Legislature Ways and Means Committee, Select Committee on Criminal Justice, 1969. 